\title{
Positive cross-regulation and enhancer sharing: two mechanisms for specifying overlapping Hox expression patterns
}

\author{
Alex Gould, ${ }^{1}$ Alastair Morrison, ${ }^{1}$ Graham Sproat, ${ }^{2}$ Robert A.H. White, ${ }^{2}$ and Robb Krumlauf ${ }^{1,3}$ \\ ${ }^{1}$ Laboratory of Developmental Neurobiology, Medical Research Council (MRC) National Institute for Medical Research, \\ London, $\mathrm{UK}_{;}{ }^{2}$ Department of Anatomy, University of Cambridge, Cambridge, UK
}

\begin{abstract}
Vertebrate Hox genes display nested and overlapping patterns of expression. During mouse hindbrain development, Hoxb3 and Hoxb4 share an expression domain caudal to the boundary between rhombomeres 6 and 7. Transgenic analysis reveals that an enhancer (CR3) is shared between both genes and specifies this domain of overlap. Both the position of CR3 within the complex and its sequence are conserved from fish to mammals, suggesting it has a common role in regulating the vertebrate $H o x B$ complex. CR3 mediates transcriptional activation by multiple Hox genes, including Hoxb4, Hoxd4, and Hoxb5 but not Hoxb1. It also functions as a selective HOX response element in Drosophila, where activation depends on Deformed, Sex combs reduced, and Antennapedia but not labial. Taken together, these data show that a Deformed/Hoxb4 autoregulatory loop has been conserved between mouse and Drosophila. In addition, these studies reveal the existence of positive cross-regulation and enhancer sharing as two mechanisms for reinforcing the overlapping expression domains of vertebrate Hox genes. In contrast, Drosophila Hox genes do not appear to share enhancers and where they overlap in expression, negative cross-regulatory interactions are observed.

Therefore, despite many well documented aspects of Hox structural and functional conservation, there are mechanistic differences in Hox complex regulation between arthropods and vertebrates.
\end{abstract}

[Key Words: Hox complex; cross-regulatory interactions; enhancer sharing; Drosophila homeotic genes; Hoxb4; transgenic mice]

Received December 18, 1996; revised version accepted February 11, 1997.

Morphological differences along the anteroposterior (AP) body axis of many animals are controlled by a conserved set of transcription factors encoded by the Hox gene family. All Hox loci are organized into complexes that display the property of colinearity, whereby the position of a gene within the complex correlates with its axial expression pattern (for review, see Duboule 1992; McGinnis and Krumlauf 1992; Krumlauf 1994; Carroll 1995|. The reasons for this colinear relationship between organization and spatial expression are not clear but are believed to involve conserved Hox regulatory mechanisms. Although considerable emphasis has been placed on the degree of similarity between the arthropod and vertebrate Hox complexes, there are significant differences.

The Drosophila melanogaster Hox cluster is naturally divided into two complexes (ANT-C and BX-C), and experimentally the BX-C itself can be split into two, with relatively minor phenotypic consequences (Lewis 1978; Kaufman et al. 1980; Struhl 1984; Tiong et al. 1987). Furthermore, the ANT-C contains several non-Hox loci

${ }^{3}$ Corresponding author.

E-MAIL r-krumlauf@nimr.mrc.ac.uk; FAX 0181-913-8658. and the Deformed (Dfl) gene is transcribed in a direction opposite to all other ANT-C Hox genes (Kaufman et al. 1990; McGinnis and Krumlauf 1992). None of the four murine Hox complexes are split apart or contain interposed non-Hox genes (Boncinelli et al. 1991; Duboule 1992; McGinnis and Krumlauf 1992). Another major difference is complex size, as Hox clusters are considerably more compact in mouse than in Drosophila. For example, the entire Hoxa complex is comparable in length with the Drosophila Antennapedia (Antp) gene (Scott et al. 1983; Schneuwly et al. 1986; Duboule and Dolle 1989|. Therefore, it appears that the vertebrate genes have remained closer to an idealized ancestral colinear organization than their Drosophila counterparts (McGinnis and Krumlauf 1992; Garcia-Fernandez and Holland 1994; Carroll 1995). This suggests that there are strong evolutionary constraints keeping vertebrate Hox genes colinear and clustered tightly.

All vertebrate $H o x$ genes are expressed in a large axial region that extends from a specific anterior boundary back toward the caudal end of the embryo. This generates a nested series of extensively overlapping domains that is not observed with all of the Drosophila ANT-C members. In Drosophila, where Hox overlaps do occur, this often results in the down-regulation of anterior 
genes through negative cross-regulation by loci expressed more posteriorly. For example, posterior to parasegment 4, Ultrabithorax $(U b x)$ and abdominal- $A$ ( $a b d$ A) repress $A n t p$ and posterior to parasegment 6, $a b d-A$ and $A b d o m i n a l-B(A b d-B)$ repress $U b x$ (Hafen et al. 1984; Struhl and White 1985; Carroll et al. 1986; Wirz et al. 1986; Bermingham et al. 1990; Appel and Sakonju 1993). It is not known whether a similar system operates in vertebrates and in general the contribution of crossregulatory interactions in maintaining the A-P boundaries and characteristic nested domains of expression is not yet clear.

The vertebrate hindbrain is organized segmentally, and develops from a series of lineage-restricted units termed rhombomeres (for review, see Lumsden and Krumlauf 1996). Within this metameric plan, Hox genes display rhombomere-specific and nested domains of expression (for review, see Keynes and Krumlauf 1994). The high degree of spatial overlap, coupled with the relatively short intergenic distances, has led to speculation that regulatory elements might be shared by vertebrate Hox genes (Simeone et al. 1988; Krumlauf 1994; van der Hoeven et al. 1996). A good example of a complex and overlapping expression pattern is provided by the Hoxb3 gene in the hindbrain (Sham et al. 1992). Here we have examined Hoxb3 expression in detail and found that it shares a rhombomere boundary with the adjacent $5^{\prime}$ $H o x b 4$ gene. Using transgenic approaches in mouse and Drosophila, we have characterized a neural regulatory element (CR3) involved in mediating the Hoxb3/Hoxb4 overlap. This work provides evidence for enhancer sharing and positive auto- and cross-regulatory interactions as mechanisms involved in specifiying a domain of expression that is shared by two adjacent vertebrate $H o x$ genes.

\section{Results}

A subset of Hoxb3 expression shares a segmental boundary with Hoxb4 at $16 / 7$

Hoxb3 provides a clear example of a gene that overlaps in expression with its neighbors in the complex (Sham et al. 1992). Previous studies have shown that in the hindbrain at 9.5 days post coitum (dpc) there is an anterior expression limit that maps to the rhombomere $4 / 5(\mathrm{r} 4 / 5)$ boundary (Wilkinson et al. 1989; Hunt et al. 1991). Here we have used whole-mount in situ hybridization to examine the dynamics of Hoxb3 expression in more detail. High levels of expression in $\mathrm{r} 5$ and $\mathrm{r} 6$ were found to be an early and transient feature of the Hoxb3 pattern with much lower levels being detectable only in these rhombomeres from $10.5 \mathrm{dpc}$ onward (Fig. 1; data not shown). At $9.25 \mathrm{dpc}$, in addition to the $\mathrm{r} 5$ and $\mathrm{r} 6$ expression, a posterior region of strong expression is present in the neural tube just caudal to the otic vesicle (Fig. 1A) and by $11 \mathrm{dpc}$ there is a sharp boundary of expression in the vicinity of the r6/7 junction (Fig. 1C). At this stage, rhombomere boundaries are not clearly visible, but we were able to determine, using a monoclonal antibody- specific for HOXB4 protein, that this later Hoxb3 boundary corresponds to that of the $5^{\prime}$ neighboring Hoxb4 gene (Wilkinson et al. 1989), and so maps to the r6/7 junction (Fig. 1, cf. C and D). Therefore, from $10.5 \mathrm{dpc}$ onward, the anterior neural expression profiles of $H o x b 3$ and $H o x b 4$ overlap. However, in the posterior spinal cord, there is a graded distribution of HOXB-4, with levels progressively lower in more posterior regions, whereas Hoxb3 remains expressed at high levels (Fig. 1E,F). This analysis demonstrates that from 9.0-11.0 dpc, the Hoxb3 gene displays two distinct domains of expression in the hindbrain, each with a different rhombomere boundary-r4/5 and r6/7.

\section{Differential transgene expression from Hoxb3 and Hoxb4 promoters}

The overlapping domains of $H o x b 3$ and Hoxb4, along with their proximity in the Hoxb complex, suggest that a common mechanism might be used to regulate both genes. We used a transgenic approach, linking a lacZ reporter gene to genomic fragments spanning the Hoxb3 locus, to search for cis-regulatory regions capable of specifying neural expression with an $\mathrm{r} 6 / 7$ boundary. Scanning $35 \mathrm{~kb}$ encompassing the entire interval between the 3' end of Hoxb4 and the proximal promoter of Hoxb2 identified only a single $3-\mathrm{kb}$ fragment with $\mathrm{r} 6 / 7$ enhancer activity (Sham et al. 1992; C. Kwan, K. Ling, S. Tsang, P. Chui, R. Krumlauf, and M. Sham, unpubl.). This control region colocalizes with an enhancer identified previously (region A) located in the intergenic region between Hoxb3 and Hoxb4 (Whiting et al. 1991), suggesting that region A might be involved in regulating both of these genes.

Region $\mathrm{A}$ is $>23 \mathrm{~kb}$ away from the proximal Hoxb3 P1 promoter and much closer to the Hoxb4 promoter. However, the presence of a noncoding exon specific for a Hoxb3 splice variant (type II) suggested that region A might contain a distal Hoxb3 promoter (P2) (Sham et al. 1992). To directly test this possibility a reporter gene lacking a promoter was placed immediately downstream of the Hoxb3 exon in region A (Fig. 2; construct 7) and assayed in transgenic mice. Neural lac $Z$ staining with an r6/7 boundary, demonstrated clearly that this fragment does contain a distal Hoxb3 promoter (P2).

To test whether region A was capable of regulating both genes, we constructed two transgenic variants capable of independently monitoring transcription from either the Hoxb 4 or the Hoxb3 P2 promoters. First, the Hoxb 4 promoter was marked by a lac $Z$ insertion into exon1 (Fig. 2, construct 1). This reporter strategy has no deleterious effects on the ability to reconstruct the overall expression pattern of Hoxb4 (Whiting et al. 1991). A comparison of transgene expression with the HOXB4 protein distribution at $10.5 \mathrm{dpc}$ indicated that the $9-\mathrm{kb}$ PstI-EcoRI fragment contains all of the elements necessary to reproduce the full Hoxb4 expression pattern with an appropriate $\mathrm{r} 6 / 7$ neural and somite 6/7 mesodermal boundary (Fig. 1, cf. F and H). lac Z expression in the neural tube was strong anteriorly and progressively 
weaker posteriorly, a characteristic feature of the endogenous Hoxb4 pattern.

Second, in the context of the same 9-kb PstI-EcoRI fragment, we monitored the activity of the Hoxb3 P2 promoter. To preserve the genomic integrity around P2 and not disrupt any regulatory elements, a splice acceptor- $-1 a c Z$ cassette was inserted $3.5 \mathrm{~kb}$ downstream of $\mathrm{P} 2$ (Fig. 2, construct 2). A similar cassette has been used to faithfully report activity from the Oct-4 promoter (Mountford et al. 1994). Neural expression from the P2 promoter displayed a sharp anterior boundary at $\mathrm{r} 6 / 7$ (Fig. 1G). Unlike expression driven from the Hoxb4 promoter, strong staining was seen in both the posterior spinal cord and mesoderm (Fig. 1, cf. E and G). Therefore, elements within the 9-kb fragment are capable of imposing an $\mathrm{r} 6 / 7$ boundary of expression on both the Hoxb4 and the Hoxb3 $\mathbf{P} 2$ promoters. It is important to note that despite the shared anterior domain, the readout of expression from these two promoters is distinctly different in posterior regions. The uniform expression of the Hoxb3 and the graded distribution of the Hoxb4 transgenes in the spinal cord are significant because they mirror the patterns of the respective endogenous genes.

\section{Conserved region 3 (CR3) is necessary and sufficient to specify an $\mathrm{r} 6 / 7$ boundary}

While the $3-\mathrm{kb}$ region A enhancer works on the Hoxb4 and Hoxb3 P2 promoters, there could be multiple r6/7 elements within this interval working independently on each promoter. Previous sequence comparisons of region A from pufferfish, chick, and mouse identified a conserved region (CR3) potentially involved in the $\mathrm{r} 6 / 7$ regulation of $\mathrm{Hoxb} 4$ (Aparicio et al. 1995; Morrison et al. 1995). To investigate the function of CR3 in mouse region $\mathrm{A}$, independent of the $\mathrm{P} 2$ promoter that it contains, we have tested the activity of various deletions on a neutral minimal $\beta$-globin promoter (Yee and Rigby 1993). The full region A (Fig. 2, construct 5) gave the expected neural pattern with a sharp anterior boundary at $\mathrm{r} 6 / 7$ and strong staining in the posterior spinal cord (Fig. 3A; Whiting et al. 1991). The deletion of CR3 from region A (Fig. 2, construct 6) specifically abolished anterior staining up to the $r 6 / 7$ boundary but gave strong expression

Figure 1. Shared boundaries and differential transgene expression from Hoxb3 and Hoxb4 promoters. $(A, C, E)$ Hoxb3 in situ hybridizations and $(B, D, F)$ HOXB4 immunostainings. $(A, B)$ Dorsal views of 9.25- to 9.5-dpc hindbrain regions. $(C, D)$ Dorsolateral views of $11 \mathrm{dpc}$ embryos showing a sharp expression boundary posterior to the otic vesicle. $(E, F)$ Lateral views of 10.5-dpc embryos. $(G, H)$ Hoxb4 expression and late neural $H o x b 3$ expression are recapitulated in transgenic embryos. Lateral views of $\beta$-galactosidase staining in $10.5-\mathrm{dpc}$ embryos that mark the activity of the Hoxb4 $(H$, construct 1$)$ and $H o x b 3$ P2 $(G$, construct 2$)$ promoters. Dashes indicate respective rhombomere boundaries. Solid arrowheads in $E$ and $G$ indicate posterior neural regions of strong staining specific for Hoxb3; open arrowheads in $F$ and $H$ denote weak posterior staining characteristic of Hoxb4. (Ov) Otic vesicle.

posteriorly (Fig. 3B). This indicates that CR3 is required for an $\mathrm{r} 6 / 7$ boundary of expression and that other neural elements within region $\mathrm{A}$ are responsible for the more posterior staining. Furthermore, either one or two copies of CR3 specify the same anterior boundary at $\mathrm{r} 6 / 7$ /Figs. $3 \mathrm{D}$ and $7 \mathrm{~A}$, below, constructs 8 and 10). Together our results imply that CR3 is the only element within the

\section{Hoxb-3}
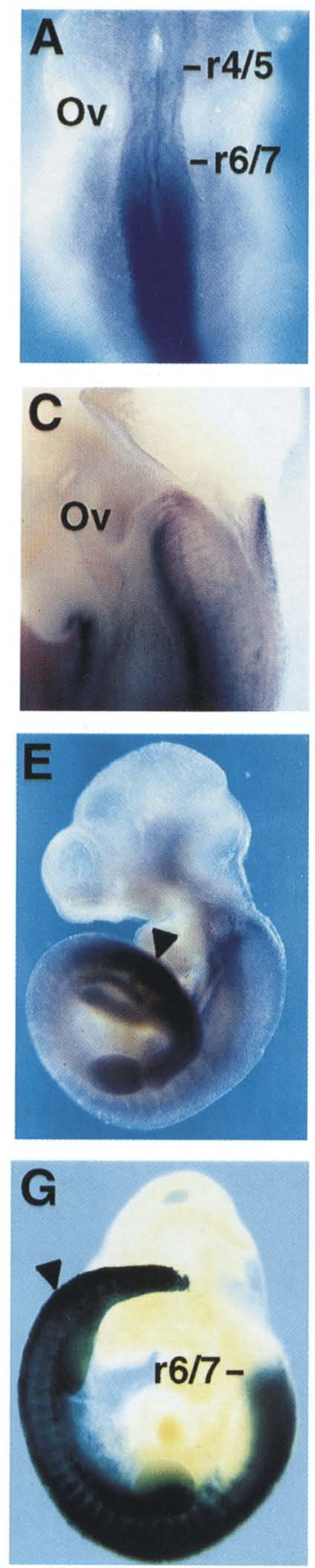

\#2
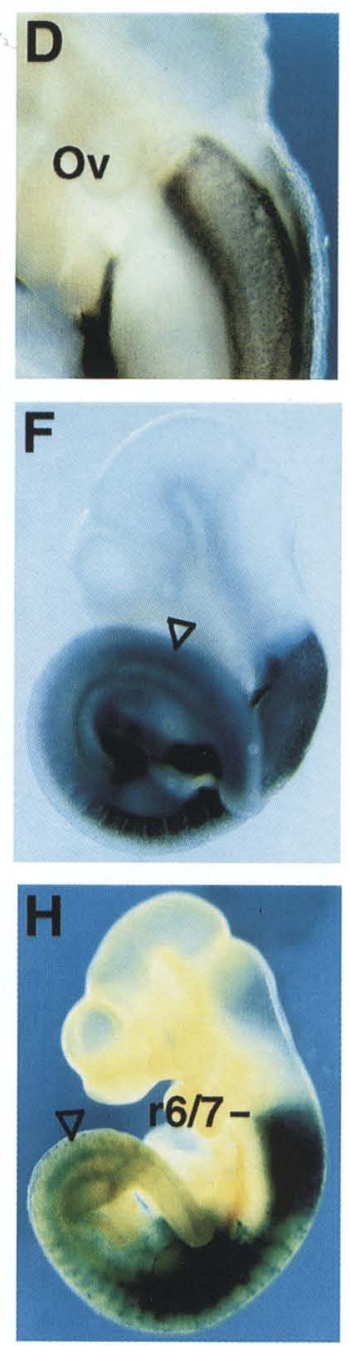

$\# 1$ 

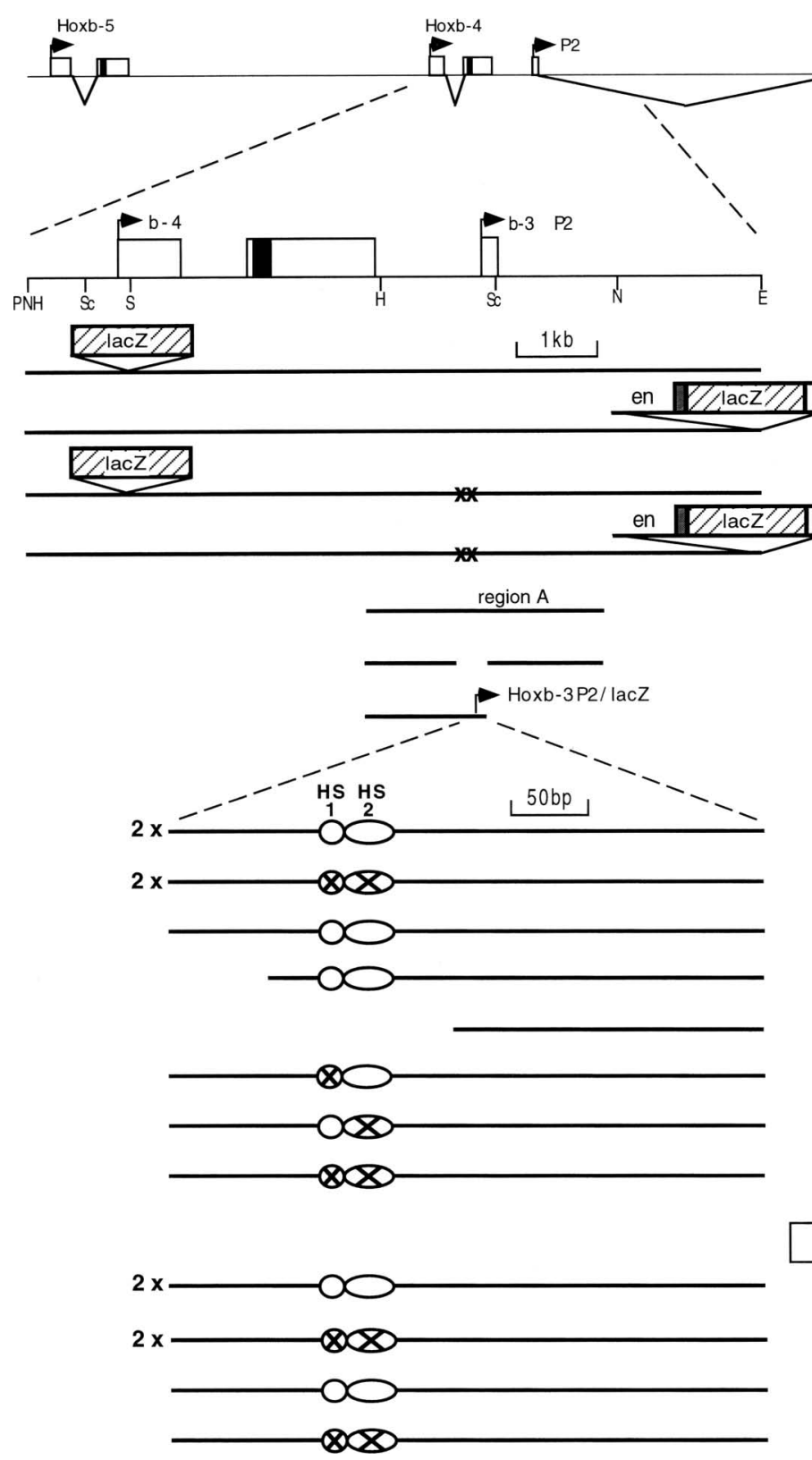

\begin{tabular}{|c|c|c|}
\hline \multicolumn{3}{|c|}{ mouse } \\
\hline$\#$ & $r 6 / 7$ & $\mathrm{Tg}$ \\
\hline 1 & + & $6 / 6$ \\
\hline 2 & + & $6 / 6$ \\
\hline 3 & - & $6 / 6$ \\
\hline 4 & - & $2 / 2$ \\
\hline 5 & + & $9 / 10$ \\
\hline 6 & - & $11 / 11$ \\
\hline 7 & + & $6 / 6$ \\
\hline 8 & + & $6 / 6$ \\
\hline 9 & - & $0 /(11)$ \\
\hline 10 & + & $4 / 5$ \\
\hline 11 & + & $8 / 9$ \\
\hline 12 & - & $0 /(10)$ \\
\hline 13 & + & $7 / 8$ \\
\hline 14 & $+1-$ & $4 / 4$ \\
\hline 15 & - & $0 /(17)$ \\
\hline & osoph & hila \\
\hline \# & $\exp ^{n}$ & $\mathrm{Tg}$ \\
\hline 16 & + & $7 / 10$ \\
\hline 17 & - & $0 / 8$ \\
\hline 18 & + & $4 / 10$ \\
\hline 19 & - & $0 / 11$ \\
\hline
\end{tabular}

Figure 2. The Hoxb3/Hoxb4 locus and constructs used for transgenesis in mice and Drosophila. E, H, N, P,S, and Sc refer to sites for EcoRI, HindIII, NcoI, PstI, SalI, and SacI present in genomic DNA. Open boxes refer to exons, solid boxes mark the position of homeodomains, and promoters are arrowed. In constructs 1-4 the position of the $1 a c Z$ reporter or the $e n-2$ intron/splice acceptor/IRES/lac $Z$ cassette is indicated. In constructs $8-19$, the positions of HS1 and HS2 are indicated by a circle and oval, respectively. A bold $\mathrm{X}$ indicates the presence of HS mutations (see Fig. 6A). For mouse constructs, the presence of an $\mathrm{r} 6 / 7$ expression boundary is indicated and $\mathrm{Tg}$ refers to the fraction of expressing transgenic lines and transients that gave a consistent pattern. For Drosophila constructs, $\exp ^{\mathrm{n}}$ indicates reproducible expression and $\mathrm{Tg}$ indicates the fraction of transformant lines that gave a consistent pattern. 9-kb PstI-EcoRI fragment capable of specifying an $\mathrm{r} 6 / 7$ boundary at $10.5 \mathrm{dpc}$.

\section{Dependence of CR3 on group 4 Hox genes}

We wanted to address the nature of the upstream components controlling CR3. Hoxb4 protein is expressed in the neural plate as early as $8.0 \mathrm{dpc}$ but CR3 is first active only at $9.25 \mathrm{dpc}$ (constructs 8 and 10; data not shown). Therefore, CR3 appears to be involved in the maintenance and not the establishment of the Hoxb4 neural domain. As it is known that Drosophila $D f d$, an ortholog of Hoxb4, maintains its expression, in part, by autoregulation (Zeng et al. 1994), we tested the ability of CR3 to function as a Hoxb4 response element (Fig. 4C-H). The endogenous $D f d$ gene can be autoactivated by a ubiqui- tous pulse of DFD protein but only in restricted ectopic locations (Kuziora and McGinnis 1988). We developed a similar assay for CR3 transactivation, using a $\beta$-actin promoter to drive Hoxb4 expression throughout the mouse embryo at low levels (Fig. 4C). This low widespread expression is sufficient to induce CR3 activity in ectopic patches but only within the confines of the CNS and only anterior to the r6/7 boundary. Transactivation by $H o x b 4$ is particularly strong in ventrolateral regions of the midbrain (Fig. 4G). Because CR3 responds to ectopic HOXB4, we tested whether it was dependent on endogenous Hoxb4 activity. Previously, in embryos homozygous for a targeted replacement allele of Hoxb4, the anterior boundary of expression in the CNS was found to be diffuse and not as sharply defined as in wild-type em- 

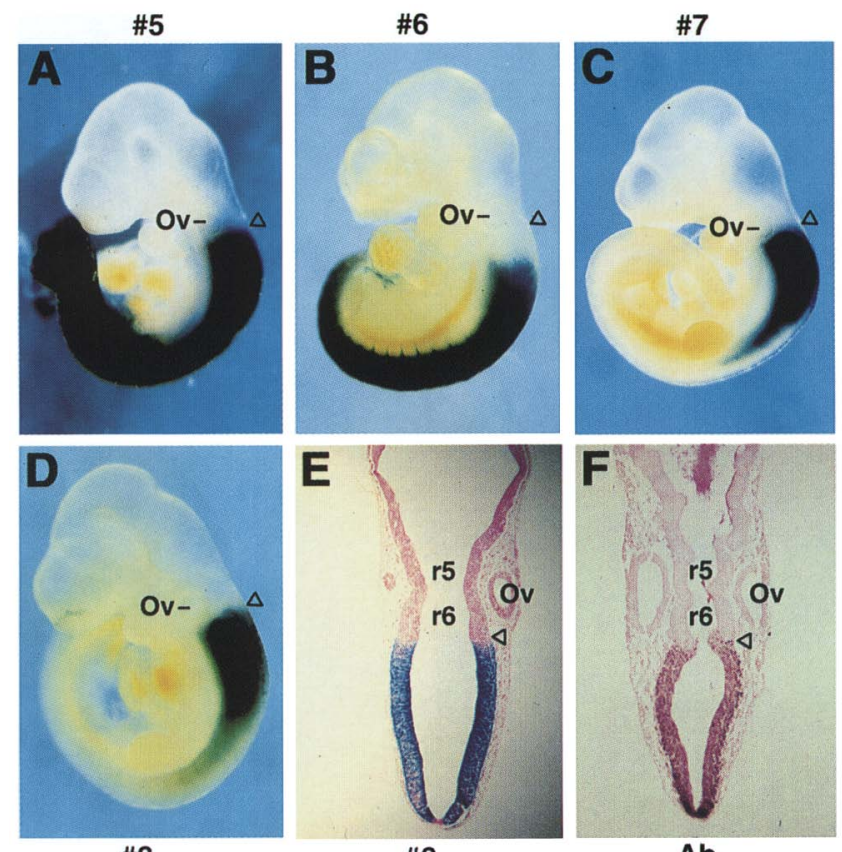

\#8

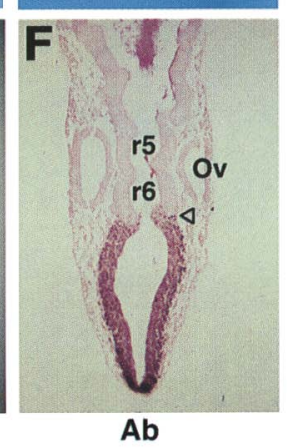

Figure 3. CR3 is necessary and sufficient to specify an $16 / 7$ expression boundary. $(A-D)$ Lateral views of 10.5 -dpc embryos transgenic for constructs 5-8. $(E, F)$ Comparisons of coronal sections of hindbrains from 10.5-dpc embryos transgenic for construct $8(E)$ or immunostained for HOXB4 $(F)$, the positions of $\mathrm{r} 5$ and $\mathrm{r} 6$ are indicated. In this and all subsequent figures an open arrowhead or Ov mark the approximate position of $r 6 / 7$ or the otic vesicle, respectively.

bryos (Ramirez-Solis et al. 1993). Surprisingly, in mouse embryos homozygous for this same mutation, we find that CR3 activity appears normal (data not shown). One explanation for the inconsistency between our reporter staining and the previous in situ expression (RamirezSolis et al. 1993) is that the transcriptional profile of the Hoxb4 promoter in the replacement allele has been disrupted in cis by the nearby insertion of the gpt and neo transcription units.

It is known that the paralog of Hoxb4, Hoxd4, also has an anterior expression boundary at $\mathrm{r} 6 / 7$ (Hunt et al. 1991). To test the possibility that Hoxd4 might be activating CR3, we ectopically expressed it and found that the CR3 lacZ reporter was also transactivated in similar regions of the CNS (Fig. 4D,H). We then looked at CR3 activity in embryos homozygous for a targeted mutation at the Hoxd4 locus (Horan et al. 1995a). As in the Hoxb4 mutants, CR3 activity was normal in these embryos (data not shown). However, when mutations in both Hoxb4 and Hoxd4 were combined, a dramatic loss of the r6/7 boundary of expression was observed in double homozygous embryos (Fig. 4B). The presence of one or more wild-type alleles at either the Hoxb4 or Hoxd4 loci is sufficient to restore the wild-type $16 / 7$ expression boundary (Fig. 4A). Therefore, the anterior $\mathrm{r} 6 / 7$ expression mediated by CR3 can be specified by either gene, illustrating an important role for auto/cross-regulatory interactions between these two paralogs.

\section{Selective response to Hox genes}

We note that in the double Hoxb4/Hoxd4 homozygotes, CR3 expression is not abolished completely, rather the rostral limit is shifted posteriorly (Fig. 4B). This suggests that other Hox genes might be involved in controlling the more posterior neural expression of CR3. Therefore, we ectopically expressed a number of Hox genes to test their ability to transactivate the enhancer. We observed no changes in reporter expression when Hoxb1, Hoxa1, Hoxb3, and Hoxb9 were used (see Materials and Methods). In contrast, ectopic Hoxb5 did induce expression in midbrain regions in a manner similar to both Hoxb4 and Hoxd4 (Fig. 4F). From the seven Hox genes tested, we conclude that members of group 4 and 5 can transactivate CR3, whereas groups 1,3 , and 9 will not. Together, the results of the loss and gain of Hox function experiments indicate that CR3 functions as a target for the action of multiple Hox genes. The group 4 genes (Hoxb4 and $H o x d 4)$ are involved in setting the $\mathrm{r} 6 / 7$ boundary of CR3, whereas more $5^{\prime}$ genes, such as Hoxb5, contribute to the activation of CR3 in more caudal regions of the CNS.

\section{Activation by Dfd, Scr, and Antp in Drosophila}

To further investigate the idea that CR3 mediates a readout that discriminates between different Hox genes, we have used the genetic advantages of the Drosophila system. Given that the HOX proteins themselves are so conserved, we wanted to test whether CR3 would direct spatially restricted expression dependent on Drosophila Hox genes. Transformant fly lines carrying CR3 linked to a minimal promoter-lac $Z$ construct were generated and analyzed for expression using an anti- $\beta$-galactosidase antibody (constructs 16 and 18). From stage 12 onward, embryos carrying such constructs displayed a consistent ventral pattern of $l a c Z$ expression, restricted to groups of cells in the posterior maxillary and anterior thoracic (T1-3) segments (Fig. 5I). Staining was most intense in the maxillary domain and weaker in anterior $\mathrm{T} 1, \mathrm{~T} 2$, and T3. Confocal double label experiments with anti- $\beta$-galactosidase and anti-DFD antibodies, indicated that the maxillary expression forms a subset of the normal $D f d$ expression domain (Fig. 5A-C). In a gain-of-function approach, similar to the transactivation assay used in the mouse, we tested the ability of CR3 to be activated ectopically by DFD when expressed from an inducible heat shock promoter (hs- $D f d$; Fig. $5 \mathrm{E}$ ). hs- $D f d$ induced ectopic expression in the dorsal clypeolabrum, anterior to the normal domain of CR3 (Fig. 5, cf. E and I). Furthermore, the maxillary transgene pattern is abolished in embryos lacking $D f d$ function (Fig. 5J). These results show that in both Drosophila and mouse embryos CR3 behaves as a $D f d /$ group 4 responsive enhancer.

In $D f d$ mutants, despite loss of the maxillary domain, thoracic expression of CR3 is unaffected (Fig. 5J). We tested the possibility that this remaining thoracic ex- 


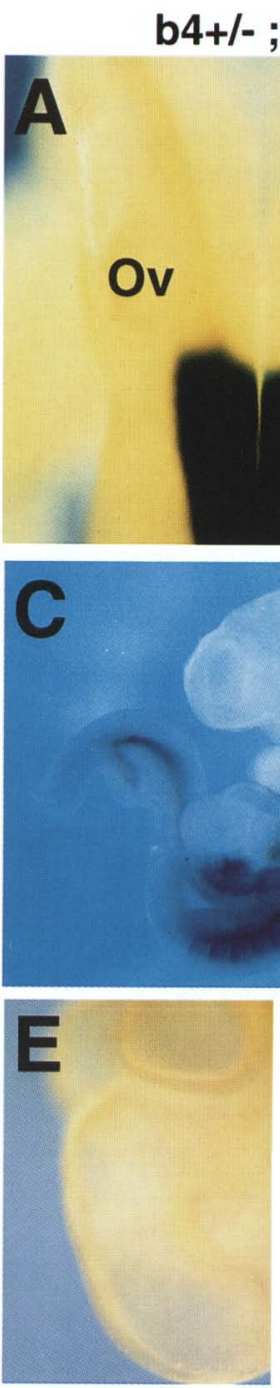

control

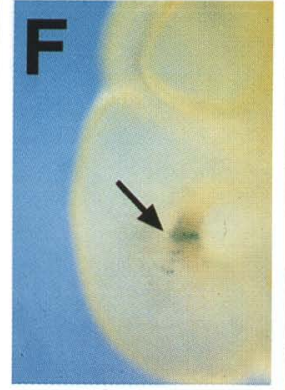

$\beta-b-5$
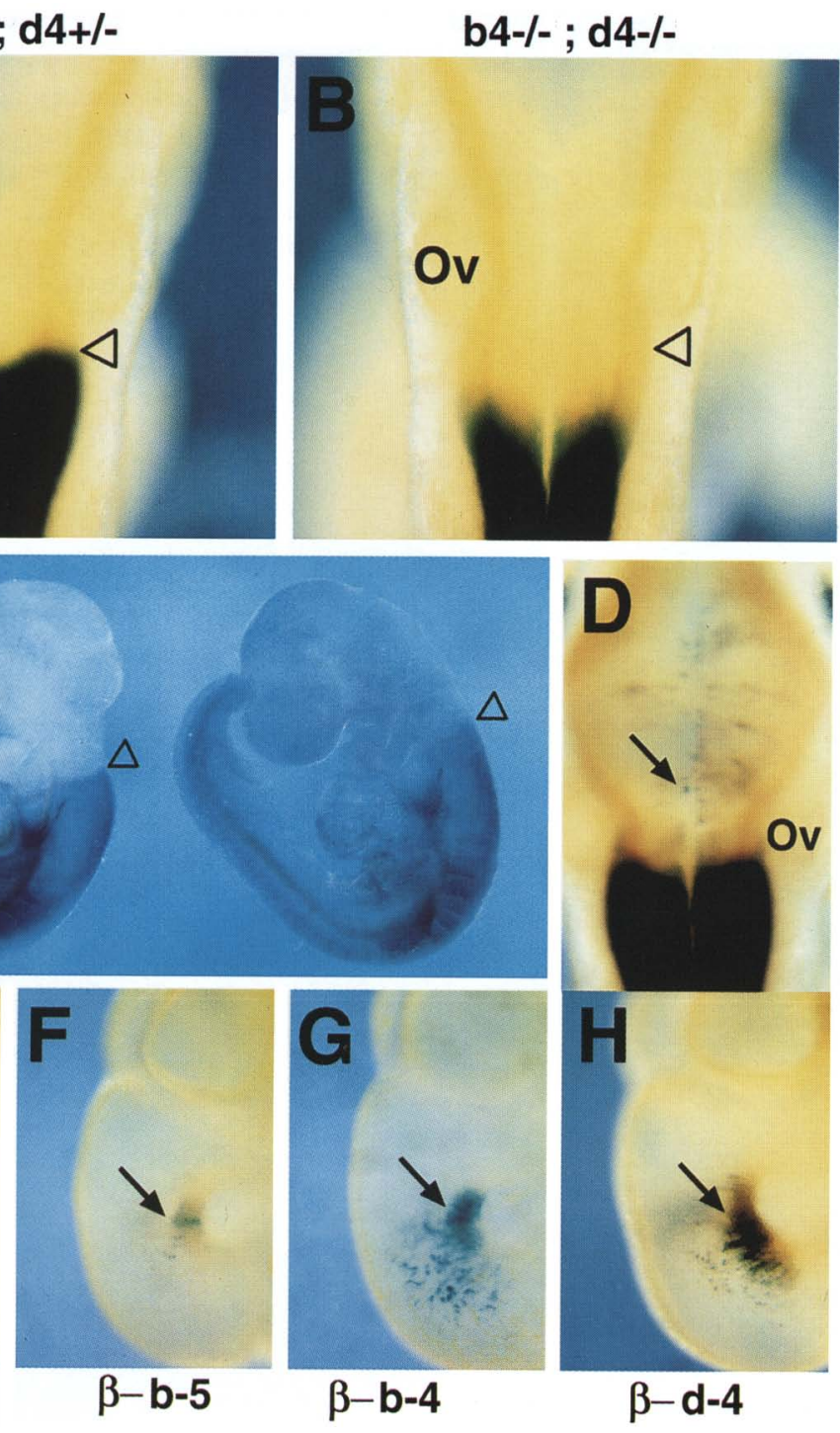

Figure 4. CR3 is regulated by group 4 and 5 genes in the mouse. $(A, B)$ Dorsal views of 10.5-dpc embryos transgenic for construct 8 and heterozyguos $(A)$ or homozygous $(B)$ for mutant alleles of both Hoxb4 and Hoxd4 showing that absence of both genes leads to loss of lacZ expression from the vicinity of r6/7. (C) Comparison between wild-type (left) and $\beta$-actin Hoxb4 transgenic (right) 9.75-dpc embryos immunostained for HOXB4. (D) Dorsal view of hindbrain of 10.5 -dpc embryo carrying a $\beta$-actin Hoxd4 construct and showing ectopic sites of expression (arrows). (E-H) Midbrain regions of control embryos transgenic for just construct $8(E)$ or embryos also transgenic for $\beta$-actin Hoxb5 $(F), \beta$-actin Hoxb4 $(G)$ and $\beta$-actin Hoxd4 $(H)$, all showing ectopic midbrain expression (arrows). pression is dependent on other Hox genes. Ubiquitous expression induced from a hs-labial (hs-lab) construct did not activate CR3 ectopically, although in some cases a modest increase in staining within the normal expression domain was observed (Fig. 5D). In contrast, clear ectopic responses to $S$ ex combs reduced (Scr) and Antp were obtained (Fig. 5F,G). Antp transactivates expression anterior to the normal CR3 domain, like $D f d$. However, $\mathrm{Scr}$ produces an ectopic response in a posterior region that is particularly striking in the first abdominal segment (A1), suggesting that it might overide a repressive role of the resident group $7 / U b x$ gene. Consistent with this, hs- $U b x$ produced a dramatic and widespread downregulation in CR3 expression (Fig. $5 \mathrm{H}$ ). Using a loss-offunction approach, we examined embryos deficient for both $S c r$ and Antp. In the absence of these Hox genes, thoracic expression is abolished, whereas the maxillary domain remains unaffected (Fig. $5 \mathrm{~K}$ ). Therefore, $D f d, S c r$, and Antp are all required for activating different aspects of the CR3 expression pattern. Ubx apparently serves a repressive role, and $l a b$ does not seem to participate (summarized in Fig. 8, below). From these results in both systems, we conclude that the ability of CR3 to discriminate between group 1 and group 4 and 5 Hox genes is conserved between mouse and Drosophila. One implication of the Drosophila experiments is that the group 6 and 7 Hox genes in the mouse are likely to have activating and repressing roles, respectively.

\section{Is CR3 a direct target of Hox genes?}

The Hox responsiveness of CR3 could be direct or indirect. To investigate the mechanism in more detail, $5^{\prime}$ deletions of CR3 (constructs 10-12) were analyzed in transgenic mice to map the elements involved. Construct 11 generated the typical CR3 pattern, but construct 12 did not express (Fig. 2; data not shown), defining a critical role for a $61-\mathrm{bp}$ region within the enhancer. Inspection of the sequence of this short region indicates the presence of two closely spaced and highly conserved TAAT motifs (HS1 and HS2 sites, Fig. 6A). Such motifs 

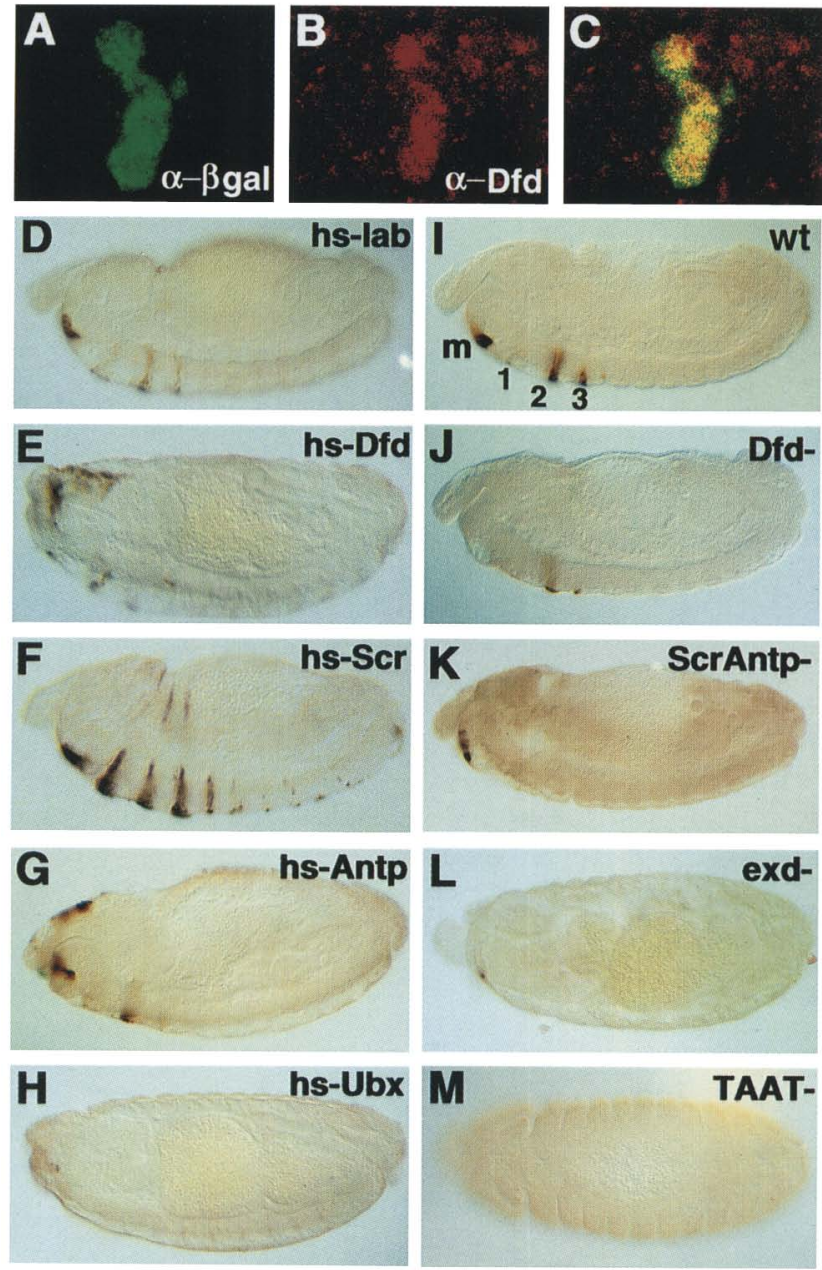

Figure 5. In Drosophila embryos, CR3 is activated by $D f d, S c r$, and $A n t p$ but repressed by $U b x .(A-C)$ Confocal triplet of maxillary/pharyngeal region of a stage 15 embryo carrying construct 16 and showing expression of $\beta$-galactosidase in green $(A)$, Dfd in red $(B)$, and the merged overlap in yellow $(C) .(D-H)$ Lateral views of heat-shocked and germ-band retracted embryos carrying construct 16 and a hs-lab $(D)$, hs- $D f d(E)$, hs-Scr $(F)$, hs-Antp $\langle G\rangle$, and hs- $U b x(H)$ construct. $(I-L)$ Germ-band retracted embryos either wild-type $\{I\}$ or homozygous for null mutations in $D f d(I), S c r$ and $A n t p(K)$, or lacking maternal and zygotic exd function $(L)$. Embryos lacking exd show low and variable levels of staining in both maxillary and thoracic segments (data not shown). $(M)$ Ventral view of embryo from line of construct 17 that contains mutations in HS1 and HS2 and lacks $\beta$-galactosidase expression.

form a core recognition sequence for many HOX proteins, including those of group 4 (Regulski et al. 1991; Popperl and Featherstone 1992; Mann and Chan 1996). This raises the possibility that these two sites mediate the Hox responsiveness of CR3 by direct binding. To test this hypothesis, the ability of a GST-HOXB4 fusion protein to interact with oligonucleotides containing HS1 and/or HS2 was assayed in vitro. We obtained specific binding of GST-HOXB4 to oligonucleotides containing HS2, or both HS1 and HS2, that was efficiently competed by wild-type but not TAAT mutant versions of the sites (Fig. 6A,B). In contrast, much weaker specific binding was obtained with oligonucleotides coutaining only HS1. Interestingly, the oligonucleotide containing HS1 and HS2 exhibited greater binding activity than one with HS2 alone. However, the size of the mobility shift indicated that additional GST-HOXB4 molecules were not being recruited to the double site, suggesting that coop-

A

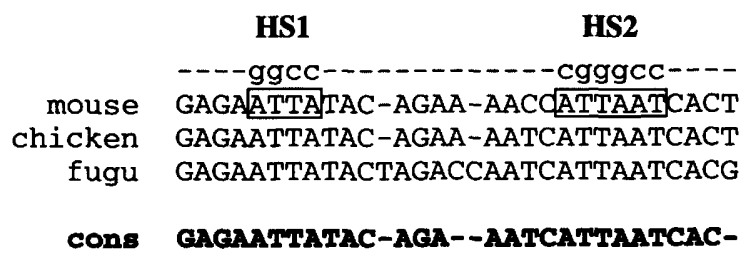

HOX / PBC

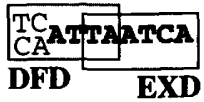

B

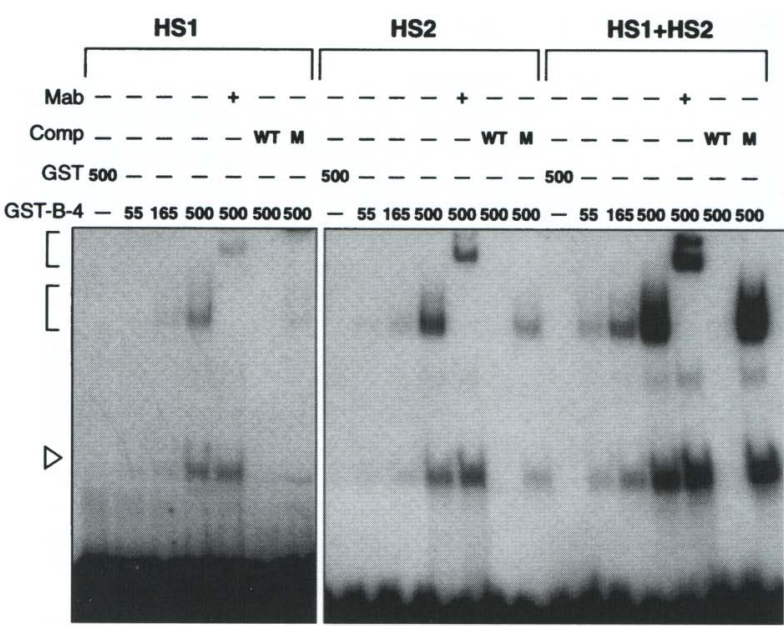

Figure 6. In vitro binding and sequence conservation of TAAT motifs. (A) Sequence alignment of $\mathrm{HS} 1 / 2$ region of CR3 from three vertebrates. Point mutations in HS1 and HS2 used in EMSA and transgenic constructs are indicated above the mouse sequence. (cons) Those residues conserved between vertebrate Hoxb4 HS1 and HS2 and HOX/PBC show the consensus for DFD and EXD binding aligned to HS2. $(B)$ Hoxb4 protein interacts strongly with HS2 and weakly with HS1 in vitro. EMSA assay with relevant sites, proteins (amounts in nanograms), presence or absence of wild-type (WT) or mutant (M) oligonucleotide competitors (comp) and antibody to HOXB4 (Mab) noted at top. Side brackets indicate shifted (lower) and supershifted (higher) complexes with GST-HOXB4 (GST-B4) protein. GST indicates control protein without $\mathrm{Hox} b 4$ open reading frame. $\triangle$ Complex containing truncated HOXB4 degradation product that does not react with Mab. (Left) Exposure is five times longer than the gel in the right panel to show weaker binding on the HS1 site. 
erative binding of multiple HOXB4 proteins is not an explanation for this effect.

To test the function of the HS1 and HS2 sites in vivo, the same series of point mutations that abolished HOXB4 binding in vitro were introduced into the CR3 enhancer (constructs 9, 13-15). Constructs containing a mutation in HS1 gave a moderate reduction in expression compared with wild-type CR3, whereas mutation of HS2 resulted in a more severe reduction in transgene expression (Fig. 7A-C). Mutations in both sites abolished all CR3-dependent expression in mouse embryos (Fig. 7D). When the mutations of the HS1 and HS2 sites were introduced into the Drosophila reporter constructs, once again, all CR3-dependent staining was abolished (Fig. 5M). These results show that the same two sites are critical for enhancer activity in both mouse and Drosophila embryos. In this regard, it is important to note that in both species, mutation in HS1 and HS2 abolishes all of the CR3-mediated expression and not just those domains dependent on group 4 Hox genes $(D f d$ and Hoxb4/Hoxd4). Because we have shown above, that intact CR3 also responds to Scr/Hoxb5, Antp, and $U b x$, it appears that HS1 and HS2 are capable of mediating all of the Hox regulatory inputs that we have observed. Together with the in vitro binding data, this strongly suggests that CR3 is a direct target for control by multiple Hox genes.

\section{CR3 activity is not completely dependent on extradenticle in Drosophila}

In vivo both HS1 and HS2 are required for full enhancer activity, yet in vitro they varied considerably in their ability to bind GST-HOXB4. Therefore the sequence contexts around HS1 and HS2 were examined, to determine whether they might account for the differential binding properties. We noted that HS2, but not HS1, was part of a bipartite HOX/PBC motif (Fig. 6A), which serves as a target site for cooperative binding between multiple HOX and PBX/EXTRADENTICLE (EXD) (PBX) EXD) family members (Chang et al. 1996; Lu and Kamps 1996; Mann and Abu-Shaar 1996). However, our in vitro assays with GST-HOXB4 and EXD or PBX-1 (PBC) proteins did not reveal any cooperative binding to HS2 or HS1 (data not shown). We still do not rule out some involvement of $\mathrm{PBC}$ proteins on HS2, because other studies with Drosophila DFD have shown a modest stimulation of the binding of DFD itself to DNA by PBC proteins in the absence of true cooperative binding between the two proteins on a target site (Zeng et al. 1994). To test whether $\mathrm{PBC}$ proteins are involved in regulation of CR3 in vivo, we have examined the exd dependence of CR3 mediated expression in Drosophila. Removing both maternal and zygotic exd contributions from the embryo resulted in a somewhat reduced level of maxillary and
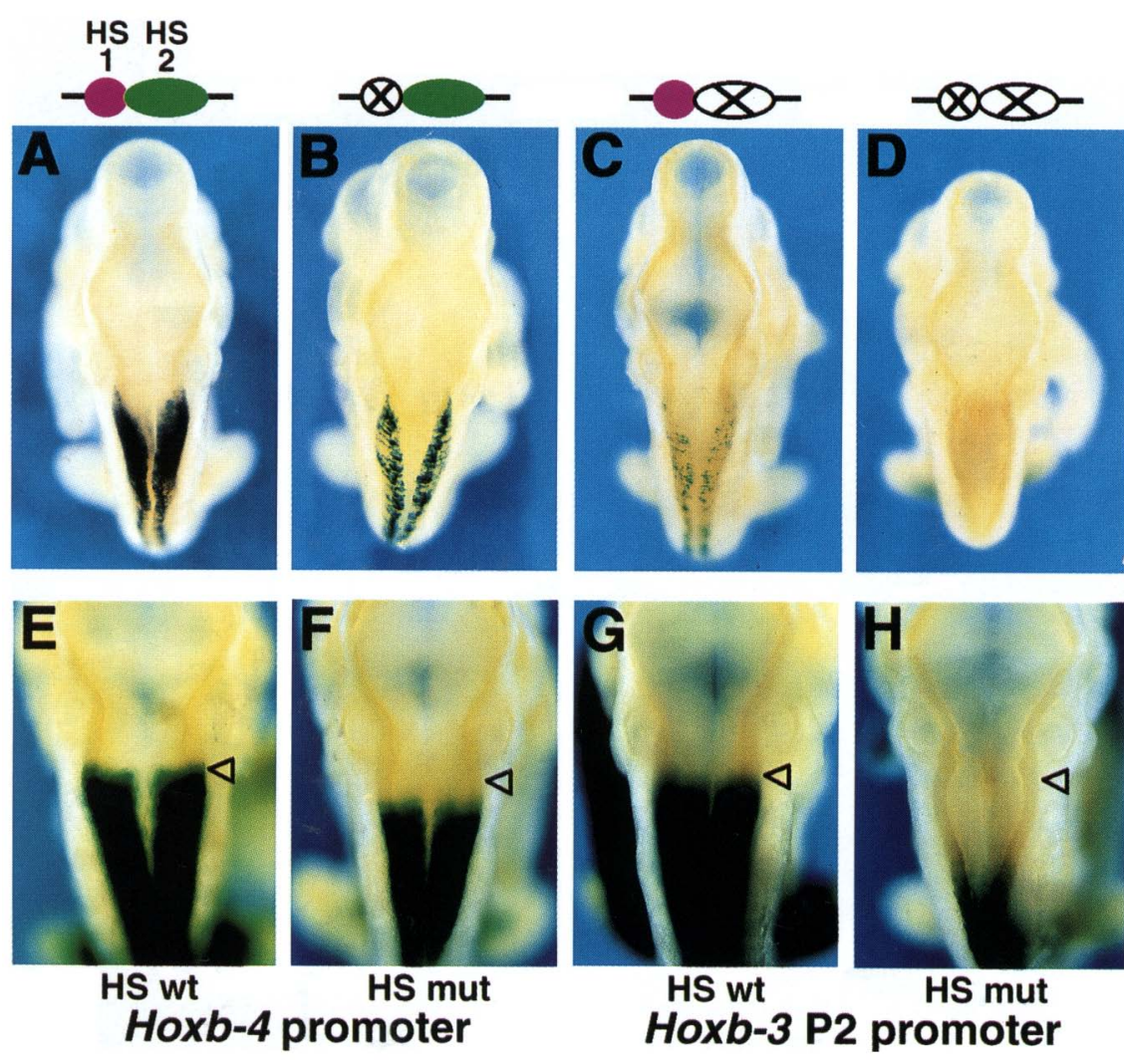

HS wt

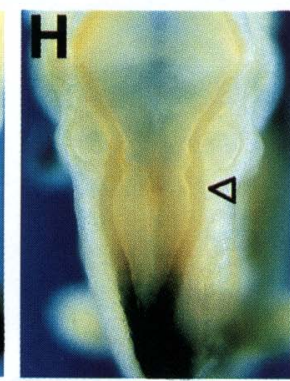

Hoxb-3 P2 promoter
Figure 7. HS1 and HS2 are essential components of CR3 and are required for $\mathrm{r} 6 / 7$ boundary specification by $\mathrm{Hoxb3}$ and Hox 64 transgenes. $(A-D)$ Dorsal views of 10.5-dpc embryos transgenic for CR3 reporter constructs $10(A), 13(B), 14(C), 15$ (D) containing combinations of the HS1 and HS2 mutations (as indicated above each panel; see Fig. 2 for details). (E,F) Dorsal views of 10.5 -dpc embryos carrying wild-type (HS wt: construct 1) or an HS1 and HS2 mutant (Hsmut: construct 3 ) variant of the $9-\mathrm{kb} \mathrm{Hoxb} 4$ promoter transgenes, respectively. $(G, H)$ Dorsal views of 10.5-dpc embryos carrying wild-type (construct 2) or HS1 and HS2 mutant (construct 4) versions, respectively, of the 9-kb $\mathrm{Hoxb}_{3}$ P2 transgenes. 
thoracic expression (Fig. 5D; data not shown). Although attenuated, expression is not abolished completely, showing that CR3 can function partially in the absence of exd. This contrasts with the previously characterized Hoxb1 autoregulatory element that is strictly dependent on exd function (Popperl et al. 1995).

TAAT motifs in CR3 are required for both Hoxb3 and Hoxb4 expression

Our experiments indicate that auto- and cross-regulatory mechanisms are used by CR3 to generate a spatially restricted pattern of expression in the neural tube with an anterior boundary at $\mathrm{r} 6 / 7$. Having mapped the two TAAT sites required for CR3 function on a heterologous $\beta$-globin promoter, we next wanted to test their role in the normal context of the intergenic region between Hoxb3 and Hoxb4. We have shown above that $9 \mathrm{~kb}$ of genomic DNA, containing CR3, is capable of specifying the Hoxb4 pattern and the late neural Hoxb3 pattern (constructs 1 and 2). These same 9-kb constructs were modified to incorporate the point mutations of both HS1 and HS2 characterized previously, leaving every other aspect identical (constructs 3 and 4).

Mutation of HS1 and HS2 resulted in a consistent posterior shift in expression driven from the Hoxb4 promoter (Fig. 7E,F). At $10.5 \mathrm{dpc}$, expression was shifted posteriorly from the vicinity of the $\mathrm{r} 6 / 7$ boundary, to a position similar to that seen when CR3 itself is deleted from region A (cf. Figs. 3B and 7F). These same TAAT mutations, tested in the context of the Hoxb3 P2 reporter transgene, caused an even more extensive posterior shift. All expression was lost in the hindbrain, but staining in the spinal cord was unaffected (Fig. 7G,H). These results show that both promoters require the HS1 and HS2 TAAT motifs to specify the correct $\mathrm{r} 6 / 7$ expression boundary. Together with the other mouse and Drosophila data above we conclude that CR3 is a direct Hox auto/cross-regulatory target, shared between the Hoxb3 and $H o x b 4$ genes.

\section{Discussion}

We have characterized a conserved neural enhancer (CR3) that is involved in maintaining expression of both the Hoxb3 and Hoxb4 genes in the posterior hindbrain. CR3 is activated by multiple Hox genes in an auto- and cross-regulatory manner to specify a common expression boundary for Hoxb3 and Hoxb4 at r6/7. The combination of transgenic and in vitro binding studies of the two TAAT motifs required for enhancer function (HS1 and HS2) strongly suggest that this control region is a direct in vivo target for multiple HOX proteins. Our analysis has uncovered two of the mechanisms contributing to the nested overlapping domains of vertebrate Hox gene expression; shared regulatory regions and positive crossregulation of a Hox gene by its $5^{\prime}$ neighbors. As the ANT-C and BX-C Hox genes do not appear, in general, to use either of these modes of regulation, it is important to compare and contrast our vertebrate findings with other studies in Drosophila.
Hox complexes: shared regulatory elements and overlapping expression patterns

The data presented here show that a single pair of HOXbinding sites within CR3 are required for the correct neural regulation of the Hoxb3 and Hoxb4 genes. Therefore, a single regulatory element is shared by two neighboring Hox genes. Sharing between these promoters could occur simultaneously or by a "flip-flop" mechanism similar to the way the locus control region of the $\beta$-globin gene cluster operates (Wijgerde et al. 1995). The bidirectional nature of CR3 implies that there are no boundary or insulator elements restricting the activity of this enhancer to only one Hox promoter.

Our transgenic analysis in the mouse indicates the presence of regulatory regions, other than CR3, within the $9-\mathrm{kb}$ interval that mediate posterior expression from the Hoxb4 and Hoxb3 P2 promoters (Fig. 3A,B). As the transcriptional readout from these posterior elements is different on the two promoters (Fig. 1G,H and Fig. 7E-H), we conclude that not all regulatory activities are shared. This selectivity could reflect intrinsic differences in the specificity of the Hoxb4 and Hoxb3P2 promoters or the presence of boundary elements capable of influencing the directionality of only certain enhancers.

Hoxb3 provides a particularly clear example of a $H o x$ pattern that shares expression domains with its neighbors in the complex, and our analysis in the murine CNS reveals that there are three different subsets of the expression pattern with anterior boundaries at $\mathrm{r} 6 / 7, \mathrm{r} 4 / 5$, and $\mathrm{r} 2 / 3$ (Fig. 1; Sham et al. 1992). Here we have shown that the CR3 enhancer shared with the $5^{\prime}$ neighbor Hoxb4, accounts for the r6/7 subset. Because the position and sequence of this enhancer is conserved in the human, mouse, chicken, and pufferfish $\operatorname{Hox} B$ complexes (Sham et al. 1992; Aparicio et al. 1995; Morrison et al. 1995) and we have found a similar r6/7 subset of the Hoxb3 expression pattern in the chick hindbrain ( $\mathrm{L}$. Ariza-McNaughton and R. Krumlauf, unpubl.), it appears that the sharing of CR3 is conserved among vertebrates. As the $\mathrm{r} 2 / 3$ subset of expression is similar to that of the 3' neighbor, Hoxb2, it is possible that Hoxb3 shares regulatory elements with the Hox genes on both sides of it in the complex. The existence of a silencer element that regulates both Hoxd10 and Hoxd11 indicates that sharing of regulatory elements is not unique to CR3 (Gérard et al. 1996). Furthermore, our previous studies have identified an enhancer (region $C_{\text {; }}$ Whiting et al. 1991) within the intron of Hoxb4 that directs a domain of neural expression with an anterior boundary similar to that of the adjacent $5^{\prime}$ gene, Hoxb5. This raises the possibility that a Hoxb4/Hoxb5 overlap in expression also occurs by enhancer sharing. Therefore, it may be that sharing of regulatory components is a widespread and important feature of vertebrate Hox complex organization.

At present there appears to be no evidence for the sharing of cis-regulatory regions between Hox genes in the Drosophila BX-C and ANT-C and it is more difficult to envisage sharing operating over the larger distances in- 
volved in these clusters. Furthermore, within the BX-C, boundary elements have been identified that are required to ensure the functional autonomy of cis-regulatory regions (Karch et al. 1985; Gyurkovics et al. 1990; SanchezHerrero 1991). The existence of boundary elements in Drosophila Hox complexes would tend to attenuate the bi-directional action of enhancer elements like CR3 (Hagstrom et al. 1996; Zhou et al. 1996). Therefore, sharing may not be present in Drosophila but could be one of the mechanisms used for generating the extensive overlaps in Hox expression observed in vertebrate species.

\section{Autoregulation and functional redundancy between paralogs}

In Drosophila, the maintenance of Hox expression is controlled by the Polycomb and trithorax group genes and by autoregulatory circuits (Bienz 1992; Kennison 1993; Orlando and Paro 1995; Simon 1995). Both direct and cell-signal mediated autoregulatory feedback loops have been characterized (Regulski et al. 1991; Bienz 1994). $D f d$ uses direct autoregulation in both the epidermis and the central nervous system, mediated by several tissue-specific and highly restricted autoregulatory elements (Kuziora and McGinnis 1988; Regulski et al. 1991; Zeng et al. 1994; Lou et al. 1995). A module of the Dfd epidermal enhancer requires binding sites for both DFD protein and the DEAF-1 cofactor (Zeng et al. 1994). DEAF-1 encodes a novel DNA-binding protein containing a short motif with some similarity to trithorax (Gross and McGinnis 1996). In addition two of the Dfd enhancer modules also contain overlapping bipartite HOX/PBC sites (Regulski et al. 1991; Lou et al. 1995). There is already some evidence that $D f d$ autoregulatory mechanisms may be conserved between Drosophila and mouse. (Awgulewitsch and Jacobs 1992; Malicki et al. 1992). When a human HOXD4 enhancer was assayed in Drosophila embryos it gave a late $D f d$-dependent pattern. However expression did not require the DFD-binding sites, arguing against conservation of a direct autoregulatory loop (Malicki et al. 1992).

Our results indicate that $\mathrm{CR} 3$ regulates the Hoxb4 promoter. The HS1 and HS2 sites in CR3 are a target for transcriptional activation by multiple group 4-6 Hox genes. In the mouse hindbrain, the only two group 4-6 genes expressed up to the $\mathrm{r} 6 / 7$ boundary at $10.5 \mathrm{dpc}$ are Hoxb4 and Hoxd4. The r6/7 limit of CR3 is only affected when both gene products are removed simultaneously and in gain-of-function experiments either Hoxb4 or Hoxd4 are able to activate CR3 ectopically. Functional redundancy between Hoxb4 and Hoxd 4 at the level of patterning individual vertebral morphologies has been demonstrated (Horan et al. 1995a,b). Here we extend those studies by showing that Hoxb4/Hoxd4 functional redundancy can operate at the level of individual genetic targets such as CR3. This demonstrates the importance of auto- and cross-regulatory interactions among the group 4 paralogs, and to distinguish these from crossregulation between different paralogy groups we use the term para-regulation.
The analysis of CR3 in Drosophila embryos reveals that it is dependent on $D f d$, responds to ectopic $D f d$, and requires the HS1 and HS2 sites. Therefore, CR3 in both Drosophila and mouse displays an evolutionarily conserved response to the $D f d$-related group 4 Hox genes. The pararegulation of CR3 we have shown in the mouse is analogous to $D f d$ autoregulation in Drosophila, and combined with the recent findings of a conserved labrelated auto-regulatory loop (Popperl et al. 1995; Chan and Mann 1996; Chan et al. 1996), this suggests that direct auto-regulatory interactions between arthropods and vertebrates are conserved.

\section{Comparison of cross-regulation in mouse and Drosophila}

In mouse, Hoxb1, Hoxa1, Hoxb3, and Hoxb9 do not induce ectopic CR3 reporter expression. However, group 5 Hox genes (Hoxb5) are able to cross-activate Hoxb4 via CR3, showing that there is a positive reinforcement of expression by the adjacent $5^{\prime}$ gene. In Drosophila, removing group $5 / \mathrm{Scr}$ function leaves $D f d$ expression unaffected, indicating the absence of any positive crossregulation of $D f d$ by $S c r$ (Jack et al. 1988; Kaufman et al. 1990). In some ectopic contexts Scr is even capable of repressing $D f d$ expression (Gonzalez-Reyes et al. 1992). This contrasts with the behavior of CR3 in Drosophila, which is activated by $D f d, S c r$, and Antp. Therefore, when in a Drosophila context, CR3 reproduces auto/ cross-regulatory interactions that are characteristic of mouse Hoxb4 and not the endogenous Drosophila Dfd gene.

We have presented evidence that expression of $H o x b 3$ from the P2 promoter is under positive cross-regulation by the group 4 Hox genes via the CR3 enhancer. This is different to the situation in Drosophila, where there is no known regulatory relationship between the group 3 genes, zerknüllt (zen) and $z 2$, and the group 4 gene $D f d$. In fact, group 3 genes in insects appear to have lost a Hox function and instead may have a role in specifying extraembryonic tissues (Rushlow and Levine 1990; Falciani et al. 1996).

In those Drosophila cases where there is extensive overlapping Hox expression, for example between the trunk selector genes $A n t p, U b x$, and $a b d-A$, posterior genes tend to partially repress the transcription of more anterior genes (Hafen et al. 1984; Struhl and Akam 1985; Carroll et al. 1986; Wirz et al. 1986; Bermingham et al. 1990; Appel and Sakonju 1993). However, in mutants where an abnormal epidermal overlap between $S c r$ and Antp is created, both negative and positive regulation of Scr by Antp can be demonstrated (Pelez et al. 1993). The significance of negative cross-regulatory interactions has been questioned by a series of elegant experiments uncoupling cross-regulation from a dominance hierarchy intrinsic to the HOX proteins themselves. Even in the absence of negative cross-regulations, posterior Hox genes can, in several cases, phenotypically suppress more anterior Hox loci (Gonzalez-Reyes and Morata 1990; Gonzalez-Reyes et al. 1990, 1992; Duboule and Morata 1994). 


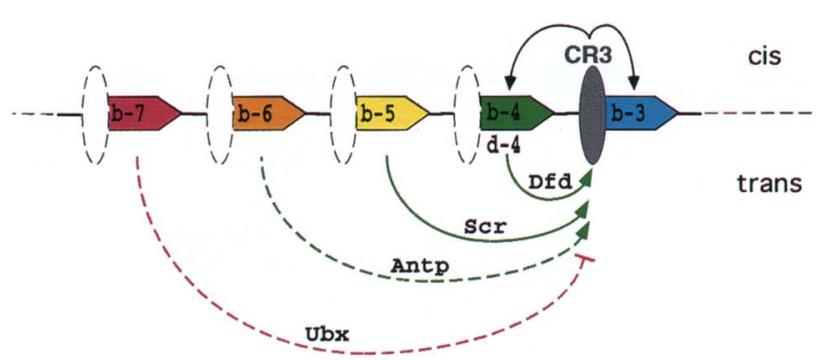

Figure 8. Cis and trans interactions of CR3. Hox genes are represented by arrow-shaped boxes with CR3 (solid oval) and other potential CR3-like elements (broken ovals) indicated. CR3 is shown juxtaposed to the $5^{\prime}$ end of the Hoxb3 gene to indicate close coupling to the Hoxb3 P2 promoter. Other CR3like elements may be linked differently to the $3^{\prime}$ neighboring Hox gene. The regulatory interactions of CR3, in cis /above broken line) and in trans (below broken line) are shown. Arrowheads and flat bars indicate positive and negative auto/cross regulations, respectively. Broken arrows indicate speculative vertebrate cross-regulations inferred from Drosophila CR3 experiments.

The studies presented here have uncovered a very different type of cross-regulation in vertebrates compared with Drosophila, that is positive in character and responsible for reinforcing a posterior subset of a Hox gene expression domain (summarized in Fig. 8). In the case of CR3, the graded expression in the CNS suggests that these positive Hox inputs do not extend all the way down the spinal cord. Moreover, the repression of CR3 activity by ectopic $U b x$ function suggests that negative cross-regulatory inputs may also operate in vertebrates in these more caudal regions. Taken together, these findings illustrate a conserved role for auto- and cross-regulatory interactions in the control of Hox expression in flies and mice but they also show that it is not possible to simply extrapolate the nature of cross-regulatory circuits between species.

\section{Conclusions}

From the experiments on Hoxb3 and Hoxb4 described here and those on other Hox genes (Zappavigna et al. 1991; Popperl and Featherstone 1992; Popperl et al. 19951, it may be that auto- and cross-regulatory interactions are generally important throughout the vertebrate complexes for maintaining appropriate nested patterns of gene expression. This raises the possibility that in many of the Hox regulatory studies where transgenes are able to function outside the complex, they do so by sensing a readout of endogenous expression domains through auto- and cross-regulation. Perhaps the clustered organization of Hox genes within a complex is essential for appropriate gene activation rather than maintenance of expression. Although we note that activation elements for the 3' Hoxa1 and Hoxb1 genes do appear to work effectively in transgenes outside of their respective complexes (Marshall et al. 1994; Frasch et al. 1995).

Our examination of a vertebrate $H o x$ expression over- lap in the hindbrain has revealed the presence of positive cross-regulation and enhancer sharing. Both mechanisms would facilitate high-level coexpression of two adjacent Hox genes. Sharing and cross-regulatory interactions do not necessarily need to be linked via a single enhancer like CR3 and it will be important to examine the contributions of each to the overall control of mouse Hox complex regulation. From an evolutionary standpoint, it is possible that the interdigitation of promoters, and sharing of regulatory regions, might provide an important constraint for maintaining the tight clustering of the vertebrate Hox complexes.

\section{Materials and methods}

Plasmid construction

Constructs 5,6 and 8-15 all contain the genomic fragments indicated in Figure 2 inserted into the SpeI site of the BGZ40 vector, which contains lacZ and a human $\beta$-globin TATA box (Yee and Rigby 1993).

Construct 7 had a blunt-ended 1.6-kb HindIII-SacI fragment from region A cloned into the PstI site of the promoter-trap vector pZA (Yee and Rigby 1993). Constructs 1-4 contained the 9-kb PstI-EcoRI genomic fragment (construct 2; Whiting et al. 1991), and in constructs 1 and 3 the lacZ gene was inserted in Hoxb4 as described (Whiting et al. 1991). In constructs 2 and 4 Hoxb3P2 was marked with a 3 ' reporter cassette containing engrailed-2 intron and splice acceptor sequences, an internal ribosome entry site (IRES), the lacZ gene, and SV40 polyadenylation sequences (Mountford et al. 1994). All deletion and point mutations were introduced by inverse PCR and verified by sequencing.

$\beta$-actin Hoxa1 and $\beta$-actin Hoxb1 have been described previously (Zhang et al. 1994; Popperl et al. 1995). Hoxb4, Hoxb5, Hoxb9, and Hoxd 4 cDNAs were PCR amplified from sequenced cDNA clones with an optimized Kozak translational start site (Kozak 1989) and inserted into HindIII-cut $\beta$-actin Hoxb1 in place of Hoxb1 cDNA sequences. In a second approach, the Wnt-1 enhancer (Echlard et al. 1994) was also used to drive expression of Hoxb3,Hoxb4, and Hoxd4 with similar results to those seen with the $\beta$-actin system, but these were confined within the Wnt-1 expression domain (data not shown).

Drosophila transposon constructs 16-19 were generated by insertion of wild-type or mutant versions of CR3 or $2 \times C R 3$ as EagI-Spel fragments into NotI-XbaI HZ50PL, containing an hsp70 TATA box, a lacZ gene, and the rosy gene as described (Gould and White 1992). The GST-Hoxb4 plasmid was constructed by insertion of a 960-bp blunted SalI-DraI cDNA fragment into the SmaI site of pGEX-1 (Smith and Johnson 1988).

\section{Generation and analysis of transgenic mice and Drosophila}

Transgenic mice were produced and analyzed for reporter staining as described (Whiting et al. 1991). Transactivation assays were performed by pronuclear injection of $\beta$-actin or Wnt constructs into fertilized eggs derived from a stable line of construct 8 . The same line was crossed to strains of mice carrying replacement alleles at the Hoxb4 and Hoxd4 loci (Ramirez-Solis et al. 1993; Horan et al. 1995a). Transgenic Drosophila were generated by P-element transformation of $c n$; ry hosts as described (Gould and White 1992). Transformant lines were crossed to mutant strains carrying the following alleles: $D f d^{R X 1}, S c r^{4}$ Ant $p^{25}$, exd $d^{B 108}$ or transformant lines carrying hs-lab, hs- $D f d$, hs-Scr, hs-Antp, or hs-Ubx transposons (Flybase 1994). Heat 
shock regimes to produce ectopic HOX proteins were $1 \mathrm{hr}$ at $37^{\circ} \mathrm{C}$, return to $25^{\circ} \mathrm{C}$ for $2 \mathrm{hr}$, followed by $1 \mathrm{hr}$ at $37^{\circ} \mathrm{C}$ and a $4-\mathrm{hr}$ recovery at $25^{\circ} \mathrm{C}$, except for hs- $U b x$, where a single 1 -hr $37^{\circ} \mathrm{C}$ heat shock was used, followed by a 1 -hr recovery at $25^{\circ} \mathrm{C}$. Embryos deficient for maternal and zygotic exd function were produced by the FLP/ovoD method (Rauskolb et al. 1993).

\section{Whole-mount in situ hybridizations and immunostaining}

Whole mouse embryos were fixed in $4 \%$ formaldehyde and stained with a monoclonal antibody specific for mouse HOXB4 (A. Gould and R. Krumlauf, unpubl.) essentially as described (Cook et al. 1995). Whole-mount in situ hybridizations using probes specific for Hoxb3 exon III or IV were performed as described (Sham et al. 1992; Wilkinson 1992). Both probes gave identical results, indicating that the $\mathrm{r} 6 / 7$ subset of transcripts include both coding exons of Hoxb3. Drosophila embryos were fixed and immunostained (Gould et al. 1990) with anti- $\beta$-galactosidase antibodies. For confocal microscopy of double label experiments with anti- $D f d$ (gift from W. McGinnis, University of California, San Diego) and anti- $\beta$-galactosidase (Cappel) antibodies, Texas red and FITC-congugated secondary antibodies (Jackson ImmunoResearch) were used. No significant cross reaction of either secondary antibody was observed.

\section{Recombinant proteins and EMSA}

Purified GST-HOXB4 fusion that lacks only the first 13 amino acids of HOXB4, was produced as described (Smith and Johnson 1988 ) except that protein was washed with PBS containing $0.1 \%$ Triton X-100 and after elution the buffer was exchanged for PBS containing $5 \mathrm{~mm}$ DTT using a Centricon-C30 (Amicon), 10\% glycerol added and stored at $-70^{\circ} \mathrm{C}$. Monoclonal antibodies against HOXB4 were purified from serum-free medium by affinity chromatography on a protein $\mathrm{G}$ column. Binding reactions for EMSA were prepared as in Popperl et. al.1995 except that $400 \mathrm{ng}$ poly[d(I-C)] was always added. Oligonucleotide sequences were as follows: HSI, CAAGAGCTAAGAAAAATGTGAGAATTATACAGAA; HS2, GAACCATTAATCACTTCTTTTCTTTAAATAC; HS1 + HS2, GAGAATTATACAGAAAACCATTAATCACTTC. Labeling was at a terminal $C$ residue using Klenow polymerase and $\left[\alpha{ }^{-32} \mathrm{P}\right] \mathrm{dCTP}$. Residue alterations for the mutant oligonucleotides were identical to those used in transgenic analysis (Fig. 6A). In each binding reaction, 50-500 ng of recombinant proteins were used and, where included, 200 $\mathrm{ng}$ of competitor oligonucleotides and $10 \mu \mathrm{g}$ of purified antibodies were added. After a 20 -min incubation on ice, complexes were separated on a $6 \%$ acrylamide $/ 2.5 \%$ glycerol $/ 0.5 x T B E$ gel run at $4^{\circ} \mathrm{C}$.

\section{Acknowledgments}

We are grateful to G. Horan and R. Behringer for Hoxd4 mutants, W. McGinnis for Dfd mutants and antibodies, M. Bienz, G. Struhl, E. Wieschaus, and the Bloomington Stock Center for fly stocks, and R. Beddington, A. Smith, and M. Featherstone for plasmids. We also thank C.-T. Kwan and M.-H. Sham for sharing unpublished data, and W. McGinnis, G. Horan, R. Mann, J. Sharpe, and L. Ariza-McNaughton for advice and discussions. A.G. was a Beit Memorial Fellow, A.M. an MRC Training Fellow, and all work was supported by the MRC and by the Wellcome Trust (R.W.).

The publication costs of this article were defrayed in part by payment of page charges. This article must therefore be hereby marked "advertisement" in accordance with 18 USC section 1734 solely to indicate this fact.

\section{References}

Aparicio, S., A. Morrison, A. Gould, J. Gilthorpe, C. Chaudhuri, P.W.J. Rigby, R. Krumlauf, and S. Brenner. 1995. Detecting conserved regulatory elements with the model genome of the Japanese puffer fish Fugu rubripes. Proc. Natl. Acad. Sci. 92: 1684-1688.

Appel, B. and S. Sakonju. 1993. Cell-type-specific mechanisms of transcriptional repression by the homeotic gene products UBX and ABD-A in Drosophila embryos. EMBO J. 12: 10991109.

Awgulewitsch, A. and D. Jacobs. 1992. Deformed autoregulatory element from Drosophila functions in a conserved manner in transgenic mice. Nature 358: 341-345.

Bermingham, J., A. Martinez-Arias, M. Petitt, and M. Scott. 1990. Different patterns of transcription from the two Antennapedia promoters during Drosophila embryogenesis. Development 109: 553-566.

Bienz, M. 1992. Molecular mechanisms of determination in Drosophila. Curr. Opin. Cell Biol. 4: 995-961.

- 1994. Homeotic genes and positional signalling in the Drosophila viscera. Trends Genet. 10: 22-26.

Boncinelli, E., A. Simeone, D. Acampora, and F. Mavilio. 1991. HOX gene activation by retinoic acid. Trends Genet 7: 329334.

Carroll, S., R. Laymon, M. McCutcheon, P. Riley, and M. Scott. 1986. The localization and regulation of Antennapedia protein expression in Drosophila embryos. Cell 47: 113-122.

Carroll, S.B. 1995. Homeotic genes and the evolution of arthropods and chordates. Nature 376: 479-485.

Chan, S.-K. and R. Mann. 1996. A structural model for a homoetic protein-extradenticle-DNA complex accounts for the choice of HOX protein in the heterodimer. Proc. Nat1. Acad. Sci. 93: 5223-5228.

Chan, S.-K., H. Popperl, R. Krumlauf, and R.S. Mann. 1996. An extradenticle-induced conformational change in a Hox protein overcomes an inhibitory function of the conserved hexapeptide motif. EMBO I. 15: 2476-2487.

Chang, C.-P., L. Brocchieri, W.-F. Shen, C. Largman, and M. Cleary. 1996. Pbx modulation of Hox homeodomain aminoterminal arms establishes different DNA-binding specificities across the Hox locus. Mol. Cell. Biol. 16: 1734-1745.

Cook, M., A. Gould, N. Brand, J. Davies, P. Strutt, R. Shaknovich, J. Licht, S. Waxman, Z. Chien, S. Gluecksohn-Waelsch, R. Krumlauf, and A. Zelent. 1995. Expression of the zincfinger gene $P L Z F$ at rhombomere boundaries in the vertebrate hindbrain. Proc. Nat1. Acad. Sci. 92: 2249-2253.

Duboule, D. 1992. The vertebrate limb: A model system to study the Hox/HOM gene network during development and evolution. BioEssays 14: 375-384.

Duboule, D. and P. Dolle. 1989. The structural and functional organization of the murine HOX gene family resembles that of Drosophila homeotic genes. EMBO J. 8: 1497-1505.

Duboule, D. and G. Morata. 1994. Colinearity and functional heiarchies among genes of the homeotic complexes. Trends Genet. 10: 358-364.

Echlard, Y., G. Vassileva, and A. McMahon. 1994. Cis-acting regulatory sequences governing Wnt-1 expression in the developing mouse CNS. Development 120: 2213-2224.

Falciani, F., B. Hausdorf, R. Schröder, M. Akam, D. Tautz, R. Denell, and S. Brown. 1996. Class 3 Hox genes in insects and the origin of zen. Proc. Natl. Acad. Sci. 93: 8479-8484. 
Flybase. 1994. The Drosophila genetic database. Nucleic Acids Res. 22: 3456-3458.

Frasch, M., X. Chen, and T. Lufkin. 1995. Evolutionary-conserved enhancers direct region-specific expression of the murine Hoxa-1 and Hoxa-2 loci in both mice and Drosophila. Development 121: 957-974.

Garcia-Fernandez, J. and P.W.H. Holland. 1994. Archetypal organisation of the amphioxus Hox gene cluster. Nature 370: $563-566$.

Gérard, M., J.-W. Chen, H. Gronemeyer, P. Chambon, D. Duboule, and J. Zákány. 1996. In vivo targeted mutagenesis of a regulatory element reguired for positioning the Hoxd-11 and Hoxd-10 expression boundaries. Genes \& Dev. 10: 23262334.

Gonzalez-Reyes, A. and G. Morata. 1990. The developmental effect of overexpressing a Ubx product in Drosophila embryos is dependent on its interactions with other homeotic products. Cell 61: 515-522.

Gonzalez-Reyes, A., M. Urquia, W. Gehring, G. Struhl, and G. Morata. 1990. Are cross-regulatory interactions between homeotic genes functionally significant? Nature 334: 78-80.

Gonzalez-Reyes, A., A. Macias, and G. Morata. 1992. Autocatalysis and phenotypic expression of Drosophila homeotic gene Deformed: Its dependence on polarity and homeotic gene function. Development 116: 1059-1068.

Gould, A., R. Lai, M. Green, and R. White. 1990. Blocking cell division does not remove the requirement for Polycomb function in Drosophila embryogenesis. Development 110: 1319-1325.

Gould, A.P. and R.A.H. White. 1992. Connectin, a target of homeotic gene control in Drosophila. Development 116: $1163-1174$.

Gross, D. and W. McGinnis. 1996. DEAF-1, a novel protein that binds an essential region in a Deformed response element. EMBO I. 15: 1961-1970.

Gyurkovics, H., J. Gausz, J. Kummer, and F. Karch. 1990. A new homeotic mutation in the Drosophila bithorax complex removes a boundary separating two domains of regulation. EMBO T. 9: 2579-2585.

Hafen, E., M. Levine, and W. Gehring. 1984. Regulation of Antennapedia transcript distribution by the bithorax complex of Drosophila. Nature 307: 287-289.

Hagstrom, K., M. Muller, and P. Schedl. 1996. Fab-7 functions as a chromatin domain boundary to ensure proper segment specification by the Drosophila bithorax complex. Genes \& Dev. 10: 3202-3215.

Horan, G., E. Kovacs, R. Behringer, and M. Featherstone. 1995a. Mutations in paralogous Hox genes result in overlapping homeotic transformations of the axial skeleton: Evidence for unique and redundant function. Dev. Biol. 169: 359-372.

Horan, G., R. Ramirez-Solis, M. Featherstone, D. Wolgemuth, A. Bradley, and R. Behringer. 1995b. Compound mutants for the paralogous Hoxa-4, Hoxb-4, and Hoxd-4 genes show more complete homeotic transformations and a dose-dependent increase in the number of vertebrae transformed. Genes \& Dev. 9: 1667-1677.

Hunt, P., M. Gulisano, M. Cook, M. Sham, A. Faiella, D. Wilkinson, E. Boncinelli, and R. Krumlauf. 1991. A distinct Hox code for the branchial region of the head. Nature 353: 861-864.

Jack, T., M. Regulski, and W. McGinnis. 1988. Pair-rule segmentation genes regulate the expression of the homeotic selector gene, Deformed. Genes \& Dev. 2: 635-651.

Karch, F., B. Weiffenbach, M. Peifer, W. Bender, I. Duncan, S. Celniker, M. Crosby, and E.B. Lewis. 1985. The abdominal region of the bithorax complex. Cell 43: 81-96.
Kaufman, T., M. Seeger, and G. Olsen. 1990. Molecular and genetic organisation of the Antennapedia gene complex of Drosophila melanogaster. Adv. Genet. 27: 309-362.

Kaufman, T.C., R. Lewis, and B. Wakimoto. 1980. Cytogenetic analysis of chromosome 3 in Drosophila melanogaster: The homeotic gene complex in polytene chromosomal interval 84A,B. Genetics 94: 115-133.

Kennison, J.A. 1993. Transcriptional activation of Drosophila homeotic genes from distant regulatory elements. Trends Genet. 9: 75-79.

Keynes, R. and R. Krumlauf. 1994. Hox genes and regionalization of the nervous system. Annu. Rev. Neurosci. 17: 109132.

Kozak, M. 1989. The scanning model for translation: An update. J. Cell Biol. 108: 229-241.

Krumlauf, R. 1994. Hox genes in vertebrate development. Cell 78: 191-201.

Kuziora, M.A. and W. McGinnis. 1988. Autoregulation of a Drosophila homeotic selector gene. Cell 55: 477-485.

Lewis, E. 1978. A gene complex controlling segmentation in Drosophila. Nature 276: 565-570.

Lou, L., C. Bergson, and W. McGinnis. 1995. Deformed expression in the Drosophila central nervous system is controlled by an autoactivated intronic enhancer. Nucleic Acids Res. 23: 3481-3487.

Lu, Q. and M. Kamps. 1996. Structural determinants within Pbxl that mediate cooperative DNA binding with pentapeptide-containing HOX proteins: Proposal for a model of a PBX1-HOX-DNA complex. Mol. Cell. Biol. 16: 1632-1640.

Lumsden, A. and R. Krumlauf. 1996. Patterning the vertebrate neuraxis. Science 274: 1109-1115.

Malicki, J., L. Cianetti, C. Peschle, and W. McGinnis. 1992. A human HOX 4B regulatory element provides head-specific expression in Drosophila embryos. Nature 358: 345-347.

Mann, R. and M. Abu-Shaar. 1996. Nuclear import of the homeodomain protein extradenticle in response to $\mathrm{Wg}$ asnd Dpp signalling. Nature 383: 630-633.

Mann, R. and S.-K. Chan. 1996. Extra specificity from extradenticle: The partnership between HOX and PBX/EXD homeodomain proteins. Trends Genet. 12: 258-262.

Marshall, H., M. Studer, H. Popperl, S. Aparicio, A. Kuroiwa, S. Brenner, and R. Krumlauf. 1994. A conserved retinoic acid response element required for early expression of the homeobox gene Hoxb-1. Nature 370: 567-571.

McGinnis, W. and R. Krumlauf. 1992. Homeobox genes and axial patterning. Cell 68: 283-302.

Morrison, A., C. Chaudhuri, L. Ariza-McNaughton, I. Muchamore, A. Kuroiwa, and R. Krumlauf. 1995. Comparative analysis of chicken Hoxb-4 regulation in transgenic mice. Mech. Dev. 53: 47-59.

Mountford, P., B. Zevnik, A. Düwel, J. Nichols, M. Li, C. Dani, M. Robertson, I. Chambers, and A. Smith. 1994. Dicistronic targeting constructs: Reporters and modifiers of mammalian gene expression. Proc. Natl. Acad. Sci. 91: 4303-4307.

Orlando, V. and R. Paro. 1995. Chromatin multiprotein complexes involved in the maintenance of transcription patterns. Curr. Opin. Genet. Dev. 5: 174-179.

Pelez, S., N. Urquia, and G. Morata. 1993. Normal and ectopic domains of the homeotic gene Sex combs reduced of Drosophila. Development 117: 917-923.

Popperl, H., M. Bienz, M. Studer, S.K. Chan, S. Aparicio, S. Brenner, R.S. Mann, and R. Krumlauf. 1995. Segmental expression of Hoxb- 1 is controlled by a highly conserved autoregulatory loop dependent upon exd/Pbx. Cell 81: 1031-1042.

Popperl, H. and M.S. Featherstone. 1992. An autoregulatory el- 
ement of the murine Hox-4.2 gene. EMBO J. 11: 3673-3680.

Ramirez-Solis, R., H. Zheng, J. Whiting, R. Krumlauf, and A. Bradley. 1993. Hox-B4 (Hox-2.6) mutant mice show homeotic transformation of cervical vertebra and defects in the closure of the sternal rudiments. Cell 73: 279-294.

Rauskolb, C., M. Peifer, and E. Wieschaus. 1993. extradenticle, a regulator of homeotic gene activity, is a homolog of the homeobox-containing human proto-oncogene pbx1. Cell 74: $1101-1112$.

Regulski, M., S. Dessain, N. McGinnis, and W. McGinnis. 1991. High-affinity binding sites for the Deformed protein are required for the function of an autoregulatory enhancer of the Deformed gene. Genes \& Dev. 5: 278-286.

Rushlow, C. and M. Levine. 1990. Role of the zerknüllt gene in dorsal-ventral pattern formation in Drosophila. Adv. Genet. 27: 277-307.

Sanchez-Herrero, E. 1991. Control of the expression of the bithorax complex abdominal $A$ and $A b d o m i n a l-B$ by cis-regulatory regions in Drosophila embryos. Development 111: 437-449.

Schneuwly, S., A. Kuroiwa, P. Baumgartner, and W. Gehring. 1986. Structural organization and sequence of the homeotic gene Antennapedia of Drosophila melanogaster. EMBO J. 5: 733-739.

Scott, M., A. Weiner, T. Hazelrigg, B. Polisky, V. Pirotta, F. Scalenghe, and M. Kaufman. 1983. The molecular organization of the Antennapedia locus of Drosophila. Cell 35: 763776.

Sham, M.-H., P. Hunt, S. Nonchev, N. Papalopulu, A. Graham, E. Boncinelli, and R. Krumlauf. 1992. Analysis of the murine Hox-2.7 gene: Conserved alternative transcripts with differential distributions in the nervous system and the potential for shared regulatory regions. EMBO I. 11: 1825-1836.

Simeone, A., M. Pannese, D. Acampora, M. D'Esposito, and E. Boncinelli. 1988. At least three human homeoboxes on chromosome 12 belong to the same transcription unit. Nucleic Acids Res. 16: 5379-5390.

Simon, J. 1995. Locking in stable states of gene expression: Transcriptional control during Drosophila development. Curr. Opin. Cell Biol. 7: 376-385.

Smith, D.B. and K.S. Johnson. 1988. Single-step purification of polypeptides expressed in E. coli as fusions with glutathione S-transferase. Gene 67: 31-40.

Struhl, G. 1984. Splitting the bithorax complex of Drosophila. Nature 308: 454-457.

Struhl, G. and M. Akam. 1985. Altered distributions of Ultrabithorax transcripts in extra sex combs mutant embryos of Drosophila. EMBO I. 4: 3259-3264.

Struhl, G. and R. White. 1985. Regulation of the Ultrabithorax gene of Drosophila by other bithorax complex genes. Cell 43: 507-519.

Tiong, S.Y., J.R. Whittle, and M.C. Gribbin. 1987. Chromosomal continuity in the abdominal region of the bithorax complex of Drosophila is not essential for its contribution to metameric identity. Development 101: 135-142.

van der Hoeven, F., J. Zákány and D. Duboule. 1996. Gene transpositions in the HoxD complex reveal a hierarchy of regulatory controls. Cell 85: 1025-1035.

Whiting, J., H. Marshall, M. Cook, R. Krumlauf, P.W.J. Rigby, D. Stott, and R.K. Allemann. 1991. Multiple spatially specific enhancers are required to reconstruct the pattern of Hox-2.6 gene expression. Genes \& Dev. 5: 2048-2059.

Wijgerde, M., F. Grosveld, and P. Fraser. 1995. Transcription complex stability and chromatin dynamics in vivo. Nature 377: 209-213.

Wilkinson, D.G. 1992. Whole mount in situ hybridisation of vertebrate embryos. In In situ hybridisation, a practical approach (ed. D.G. Wilkinson), pp. 75-83. IRL Press at Oxford University Press, Oxford, UK.

Wilkinson, D.G., S. Bhatt, M. Cook, E. Boncinelli, and R. Krumlauf. 1989. Segmental expression of Hox-2 homeobox-containing genes in the developing mouse hindbrain. Nature 341: 405-409.

Wirz, J., L. Fessler, and W. Gehring. 1986. Localization of the Antennapedia protein in Drosophila embryos and imaginal discs. $E M B O$ J. 5: 3327-3334.

Yee, S.-P. and P.W.J. Rigby. 1993. The regulation of myogenin gene expression during the embryonic development of the mouse. Genes \& Dev. 7: 1277-1289.

Zappavigna, V., A. Renucci, J. Izpisua-Belmonte, G. Urier, C. Peschle, and D. Duboule. 1991. Hox-4 genes encode transcription factors with potential auto- and cross-regulatory capacities. EMBO J. 10: 4177-4188.

Zeng, C., J. Pinsonneault, G. Gellon, N. McGinnis, and W. McGinnis. 1994. Deformed protein binding sites and cofactor binding sites are required for the function of a small segment-specific regulatory element in Drosophila embryos. EMBO I. 13: 2362-2377.

Zhang, M., H.-J. Kim, H. Marshall, M. Gendron-Maguire, A.D. Lucas, A. Baron, L.J. Gudas, T. Gridley, R. Krumlauf, and J.F. Grippo. 1994. Ectopic Hoxa-1 induces rhombomere transformation in mouse hindbrain. Development 120: 2431-2442.

Zhou, J., S. Barolo, P. Szymanski, and M. Levine. 1996. The Fab-7 element of the bithorax complex attenuates enhancerpromoter interactions in the Drosophila embryo. Genes \& Dev. 10: 3195-3201. 


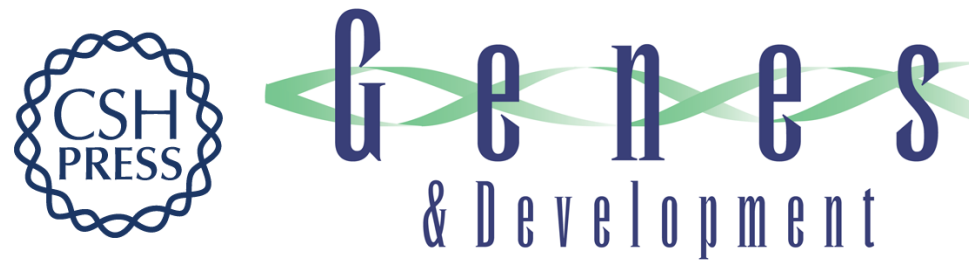

\section{Positive cross-regulation and enhancer sharing: two mechanisms for specifying overlapping Hox expression patterns.}

A Gould, A Morrison, G Sproat, et al.

Genes Dev. 1997, 11:

Access the most recent version at doi:10.1101/gad.11.7.900

References This article cites 83 articles, 28 of which can be accessed free at:

http://genesdev.cshlp.org/content/11/7/900.full.html\#ref-list-1

License

Email Alerting

Service

Receive free email alerts when new articles cite this article - sign up in the box at the top right corner of the article or click here.

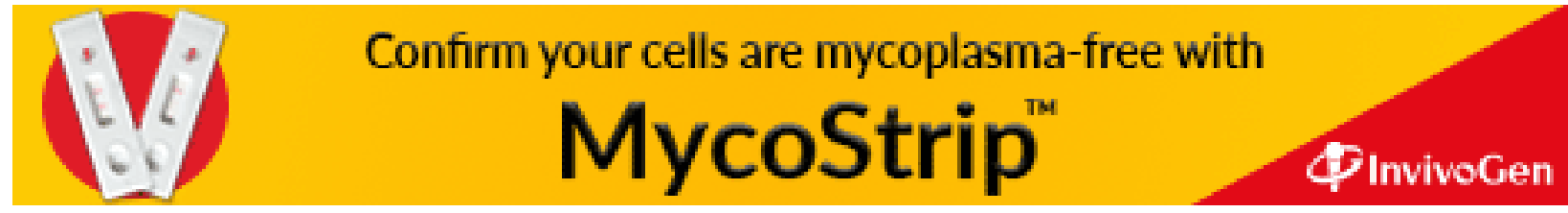

